\title{
DIREITOS HUMANOS E O PAPEL DOS MOVIMENTOS FEMINISTAS NO DISCURSO NEOLIBERAL
}

\author{
Tainá Machado Vargas ${ }^{1}$ \\ Paula Pinhal de Carlos ${ }^{2}$
}

RESUMO:

Este trabalho tem por objetivo realizar uma averiguação inicial acerca das principais características que conformam o que pode ser entendido como processo de "neoliberação" das estruturas sociais. Para tanto, usaremos como marco inicial a relação conflituosa entre a ordem econômica e os movimentos de resistência feminista, após o episódio francês maio de 1968. A partir de uma revisão bibliográfica sobre tema do neoliberalismo, abordarei análises psicológicas a respeito do que vem a ser percebido como uma nova narrativa de autogestão disciplinar. A governança neoliberal passará a ser descrita por um conjunto de práticas discursivas, capaz de expressar o incremento de uma governabilidade que reforçaria o modo de gestão econômica como um instrumento de gestão social. Esse fenômeno guia práticas políticas e internaliza valores de mercado dentro das democracias globais. Pretende-se explorar a conexão entre abordagens: econômicas; políticas; e de gênero, essencialmente centrais para se refletir sobre as investidas de poder nas sociedades neoliberais do "hiperdesempenho", aplicadas ao futuro. Onde as relações de produtividade se estabelecem de forma diferente, em razão dos múltiplos papéis funcionais esperados das mulheres. A presente pesquisa irá se restringir a discussão de questões teóricas, sem perder de vista a potencialidade de reflexões sobre os mais diversos tipos de violência que essas relações costumam avançar.

${ }^{1}$ Graduada pela Pontifícia Universidade Católica (PUCRS,) bolsista da (CAPS/PROSUC) no curso de Mestrado em Direito da Universidade La Salle (UNILASALLE), integrante do grupo Prismas e do Grupo de pesquisa CNPq Efetividade dos direitos e Poder Judiciário.

*<tai.vargas@hotmail.com>

${ }^{2}$ Graduada em Ciências Jurídicas e Sociais pela Unisinos, mestre em Direito pela mesma Universidade e doutora em Ciências Humanas (área de concentração Estudos de Gênero) pela UFSC. Professora assistente III da Universidade La Salle. *<paulapinhal@ hotmail.com> 
Palavras Chaves: Gênero; Neoliberalismo; Trabalho; Democracia

\section{HUMAN RIGHTS AND THE ROLE OF FEMINIST MOVEMENTS IN NEOLIBERAL SPEECH}

This work aims to carry out an initial investigation on the main aspects that conform what can be called as neoliberation process of social structures. The economic role of neoliberalism is to be found in the conflict of human crisis, is the mission of the human republic of 1968 . perceived as a new narrative of disciplinary self-management. Neoliberal governance will be described by a set of discursive practices, capable of expressing the increment of a governance that reinforces the way of management as an instrument of social management. This guide document is policy and internalizes market values within global democracies. The aim is to explore a connection between approaches: economic; policies; and of gender, essential to main analytics for neo-liberal societies' investment in "hyper-performance," demanded by the future. Productivity news is set differently because of the various leaflets expected from women. A current research will restrict a discussion of theoretical issues without losing the potentiality of reflections on the more advanced aspects.

Keywords: Gender; Neoliberalism; Job; Democracy

\section{INTRODUÇÃO:}

Para esclarecer o propósito econômico do conceito que iremos abordar, cabe dizer inicialmente que não compreendemos por neoliberalismo como sinônimo da velha política autorregulatória de Estado mínimo. Neoliberalismo, nos termos dos autores que iremos estudar, está ligado à concepção de uma nova racionalidade de governança global. Algo mais próximo ao sentido de uma subjetividade psicológica que governa modelos de dever-ser e bem-estar. Infiltra-se nas práticas institucionais e nos entendimentos da prática social para torná-los mais produtivos sob um viés, plenamente, econômico. Essas intenções quando filtradas pelo componente político, histórico e cultural, também instituem a prática da 
concorrência entre os mercados, e da competitividade entre indivíduos e setores privados. O neoliberalismo enquanto gestão psicológica da vida é dotada de certa plasticidade ideológica e discursiva. Isso faz com que, principalmente, as identidades, o reconhecimento e o coletivismo dos indivíduos sejam afetados por esse fenômeno em primeira instância.

Comandados por processos de engenharia política e econômica, o neoliberalismo é um sistema organizado pela lógica da concorrência e do individualismo exacerbado. Os efeitos disso, a par do cenário capitalista globalizado, geram um impacto imenso na forma como o trabalho é organizado nas sociedades marcadas por uma forte regulação administrativa, onde o papel do Estado (como agente "social” e "educador"), também se faz presente na produção de bens e serviços, no compromisso de repasse salarial entre as classes sociais e na distribuição dos ganhos de produtividade entre os trabalhadores.

É nesse sentido que o trabalho deseja explorar a crítica em torno do problema do reconhecimento e da identidade, como uma "armadilha", proposta pelo neoliberalismo progressista. Uma das estratégias que constitui a iniciativa neoliberal no campo do trabalho é a desarticulação da memória e de uma cultura política de resistência aos abusos econômicos, a favor da igualdade de direitos e da justiça social. Sendo assim, caberá a essa pesquisa explicar até que ponto esse fenômeno implicaria na exclusão das mulheres das principais esferas decisórias sobre os seus próprios direitos, sobretudo, para decidir sobre garantias especiais ligadas às suas condições do trabalho.

Ademais, a luta por direitos sempre existiu como forte expressão pluralista dos segmentos vinculados ao movimento de mulheres por justiça e igualdade. No entanto, o enfoque desse trabalho se concentrará nas abordagens feministas, que se opõe ao enfrentamento do capitalismo e da injustiça de gênero. Para isso, questiona-se em que medida a crescente ascensão das iniciativas neoliberais, a partir da globalização, começou a avançar sobre a politização das demandas de gênero?

O objetivo desse artigo é suscitar algumas discussões entre os processos de transformação cultural pelo qual passaram os movimentos feministas, frente ao seu sucesso em politizar o social e o pessoal, e o seu fracasso em agenciar mudanças na cultura institucional (seja na esfera pública e na esfera privada). De modo geral, os movimentos feministas protagonizaram grandes avanços sociais no passado, como a abolição da 
escravatura, o sufrágio universal, a prostituição infantil, o assédio sexual, o ingresso profissional nas universidades e nos mercados de trabalho, a desigualdade salarial, os direitos sexuais e reprodutivos. No presente, parecem não representar grandes evoluções, em termos de efeito comportamental e nem de mudança institucional, para espaços ambos os gêneros ${ }^{3}$ (FRASER, 2009. p,14) para emancipar-se das desigualdades produzidas pelo sistema econômico.

Inicialmente, apresentaremos a compreensão do que vem a ser entendido como fenômeno do neoliberalismo, segundo determinados autores, que contextualizam seus efeitos nas sociedades mundiais em duas partes. Em um primeiro momento, pretende-se descrever de que forma ocorre a institucionalização (geral) do sujeito neoliberal, a partir da crítica de autores como Chistian Laval, Pierre Dardot, Vladimir Safatle e Byung-Chul Han.

Em segundo momento, descreveremos a violência econômica, que prevalece sobre as demais e determina padrões de mercado através das relações concorrenciais entre os gêneros através dos escritos teóricos de Nancy Fraser e Renata Gonçalves. Com ênfase na trajetória política da segunda onda do movimento feminista, buscaremos analisar se o neoliberalismo se impõe como um novo espírito do capitalismo. Uma nova razão psicológica de acostumar-se com a vida, com a diferença e os afetos nas sociedades contemporâneas. Verificaremos se o papel do patriarcado permanece presente na transição de valores do capitalismo controlado pelo Estado para uma nova racionalidade pós-liberal, ou neoliberal androcêntrica.

\section{A DISCIPINA DO SUJEITO NEOLIBEAL QUE HABITA A SOCIAL DEMOCRACIA.}

Inicialmente associado à Margareth Thatcher na Inglaterra (1979 - 1990) e a Ronald Reagan (1981-1989) nos Estados Unidos, o neoliberalismo pode ser entendido como o prolongamento de um novo projeto social, comprometido em encarnar uma nova razão para as presenças do capitalismo contemporâneo. Neste cenário, a biopolítica descrita por Foucault

${ }^{3}$ Não se está tentando negar as transformações culturais e nem institucionais, originárias da luta dos movimentos feministas, por mais direitos às mulheres. O que se questiona é a pouca adesão dessas transformações aos ambientes institucionais e a descontinuidade da cultura em acompanhar o aparato dos poderes públicos ao assegurar a efetividade dessas conquistas. A lei Maria da Penha, por exemplo, não se mostra como instrumento legislativo capaz de solucionar o numero de violências e de mortes praticadas por agressores homens. 
na obra "Vigiar e Punir" (FOUCAULT, 1987), deixa de atribuir a governação do Estado ao domínio de uma relação de docilidade-utilidade convencional. A grande virada neoliberal consiste em alterar as mesmas dinâmicas aplicada à política de condicionamento dos corpos, de apelo fundamental às sociedades, que se organizava no modelo centralizador do capitalismo de estado. As tecnologias do poder passam a ser incorporadas à forma de vida organizacional dentro do sistema capitalista, na afirmação da governabilidade do $e u$ e nas pautas identitárias dos movimentos sociais.

Conforme (Dardot; Laval, 2016), o neoliberalismo pode ser entendido como o prolongamento de um novo projeto social, comprometido em encarnar uma nova razão para as presenças do capitalismo contemporâneo. Neste cenário, a biopolítica descrita por Foucault assume um apelo fundamental, não mais voltado a criticar o modelo centralizador do Estado clássico, permeável pela lógica de interesses públicos. As tecnologias do poder passam a ser incorporadas à forma de vida organizacional dentro do sistema capitalista neoliberal, na afirmação da governabilidade do $e u$, nas pautas identitárias dos movimentos sociais, na vida cidadã.

A política neoliberal parece, sobretudo, constituir uma resposta política a crise econômica e social do regime fordista de acumulação do capital. Esses sistemas questionavam profundamente a regulação keynesiana macroeconômica, a propriedade pública das empresas, o sistema fiscal progressivo, a proteção social e especialmente regulamentações em matéria de direto do trabalho.

“É inegável que a virada dos anos 1970-1980 tenha mobilizado objetivos para se alcançar a estratégia neoliberal, a começar pela modificação na estrutura do Estado social, desmantelando-o através da política de privatizações das empresas públicas, entre outras iniciativas (DARDOT; LAVAL, 2016, p.190)".

O novo cenário social descrito pela 'razão governamental' (DARDOT; LAVAL, 2016) descreve o neoliberalismo como uma nova sentinela política do interesse econômico. Desta forma, dirigir a administração do Estado passa a ser a nova tarefa benthaniana ${ }^{4}$, recriada por Hayek, Friedman e Von Mises, para efeitos de reformular o escopo social sobre a

\footnotetext{
${ }^{4}$ Referência a Jeremy Bentham, principal difusor da teoria ético-normativa do utilitarismo, principal expoente do liberalismo clássico. O intuito é apresentar o novo modelo socioeconômico neoliberal, designado por novos economistas modernos (a partir de 1980) ao resto das economias mundiais.
}

Revista de Direitos Humanos e Efetividade | e-ISSN: 2526-0022 | Porto Alegre | v. 4 | n. 2 |

p. $73-93$ | Jul/Dez. 2018 
orientação político-redistributiva e assistencial das instituições públicas. O marco teórico inicial das primeiras diretrizes neoliberais está relacionado ao Colóquio Walter Lippmann ${ }^{5}$, em 26 de agosto de 1938 (CHOMSKY, 1999). Isso se dá, sobretudo, em relação ao controle produtivo das relações trabalhistas e das demandas por igualdade de gênero ${ }^{6}$ (DARDOT; LAVAL, 2016, p.71). Esse fato vêm nos conduzindo a um efeito prático, inversamente proporcional à riqueza acumulada pelas empresas líderes da iniciativa privada: a perda significativa de visibilidade institucional dos mais pobres, a falta de influência destes nas pautas políticas e identitárias de gênero, e a diminuição do poder emancipatório dos indivíduos em reger as suas vidas (CHOMSKY, 1999, p. 9).

As expectativas dessas narrativas sociais vêm se confirmando, exponencialmente, desde o resultado do Fórum Econômico Mundial de DAVOS, em 2002 ${ }^{7}$ A pesquisa internacional coordenada pelo Instituto Gallup International, realizada sobre a percepção geral das instituições democráticas e financeiras, apurou grande receio das populações mundiais ao dissertar sobre o tema da confiabilidade. Cerca de menos de $33 \%$ da população brasileira não acredita no modelo desempenhado pelas instituições estatais, principalmente jurídicas e policiais, em atender aos interesses sociais. Em relação às grandes empresas multinacionais, como bancos e associações internacionais tais como o FMI, foram consideradas as instituições nas quais as populações menos confiam. Todo esse descontentamento geral sobre o funcionamento dos sistemas democráticos não despertam tantas coincidências assim.

A divulgação de pesquisas recentes sobre a política de Terceirização do Trabalho ${ }^{8}$, que pode ser compreendida como uma medida neoliberal estendida a todas as categorias profissionais no Brasil desde março de 2017. Conforme um Estudo elaborado pela Central

\footnotetext{
${ }^{5}$ (Paris, 26 de Agosto de 1938) - Conferência de intelectuais que buscava construir um novo liberalismo em rejeição às versões clássicas do coletivismo, do socialismo e do liberalismo (laissez-faire). É apontado por muitos autores como o momento de fundação no Neoliberalismo. (DARDOT; LAVAL, 2016, p.71).

${ }^{6} \mathrm{~A}$ definição de gênero adotada remete à percepção de Joan Scott sobre a relação classificatória social entre os sexos, sem descontextualizar as mulheres enquanto sujeitos-protagonistas da história, da política e da economia. Nesse sentido, essas relações entre os gêneros já estão imbricadas em relações de poder.

${ }^{7}$ Dados extraídos da pesquisa publicada pelo jornal Folha de São Paulo São Paulo, segunda-feira, 11 de novembro de 2002. <https://www1.folha.uol.com.br/fsp/folhatee/fm1111200226.htm> Acesso: 16-jul-18.

${ }^{8}$ Nesse sentido, compreende-se a reforma trabalhista como uma política neoliberal, que fragiliza os vínculos empregatícios e as garantias de direitos associados aos contratos amparados na CLT.
} 
Única dos Trabalhadores - CUT (2014) ${ }^{9}$, afirma que os trabalhadores terceirizados recebem $25 \%$ menos em salários, e trabalham 7,5\% (3 horas) a mais que outros empregados. A estabilidade da terceirização atinge menos da metade do tempo do emprego convencional, sobre as proteções celetistas. Os seus resultados confirmam um índice de reprovação de $81 \%$ entre a população, considerando critérios de discrepância regionais. Em relação à proposta de Reforma da Seguridade Social pelo governo em redefinir a idade mínima da aposentadoria, exibe um percentual que beira à unanimidade $93 \%$ de reprovação, em todos os Estados do país pesquisados. De acordo com o diagnóstico de Wendy Brown, o fenômeno de incorporação ou 'neoliberalização' da sociedade pelo próprio Estado, age como facilitador político do neoliberalismo, a partir da sua interferência negativa nos serviços públicos.

“(..) Como instrumento da política econômica do Estado, com o desmantelamento dos auxílios sociais, da progressividade do imposto e outras ferramentas de redistribuição de riquezas de um lado, e como o estímulo da atividade sem entraves ao capital mediante a desregulamentação do sistema de saúde, do trabalho e do meio ambiente de outro" (BROWN, 2007, p.37)".

O mercado, lentamente, trata de assumir a posição virtuosa como palco da democracia trabalhista, e o Estado como palco da ineficiência e da corrupção que se enraíza na sociedade (SOUZA, 2015). No entanto, intuir que a separação de ambos é algo possível é uma ilusão. O mercado necessita do poder coercitivo de polícia, ou seja, da violência estatal e das instituições judiciais para reprimir greves e garantir que os contratos sejam cumpridos. De igual forma, o Estado necessita da intervenção da iniciativa privada para ombrear despesas públicas e angariar investimentos para alimentar a sua receita fiscal, por exemplo. No entanto, quando ambos os pares disputam o mesmo espaço social, medindo e articulando forças, evidencia-se que onde há corrupção sistêmica, provocada e induzida pelo meio político, essa não subsiste quando provocada por interesses de mercado (SOUZA, 2015, p. 100). E a reforma política, que abriga esse pacto neoliberal com o Estado pela Terceirização dos recursos trabalhistas, não é o início do fim.

${ }^{9}$ Dossiê acerca do impacto da terceirização sobre os trabalhadores e propostas para garantir a igualdade de direitos. < https://www.cut.org.br/system/uploads/ck/files/Dossie-Terceirizacao-e-Desenvolvimento.pdf> 30-jan2019. 
Segundo CHOMSKY (1999), as ações especulativas estrangeiras sobre os monopólios estatais, foram concedidas pela presença (ou ausência) negativa do Estado, em manter-se à frente da coisa pública. O que onerou ainda mais os custos dos serviços essenciais à população. Tudo isso remete "a percepção popular de que somente a elite se beneficiou com a transição para a democracia" (CHOMSKY, 1999, p.61). Essa dupla via de suspeição e dependência financeira dos mercados externos e dos governos burocratas, afetou de modo geral, as relações de credibilidade entre as pessoas. Sobretudo, a crença sistêmica no fundamento na justiça e no exercício dos direitos civis das sociedades democráticas. Posto que "As pessoas não têm outros direitos além daquilo que podem obter e esperar do mercado de trabalho não regulado" (CHOMSKY, 1999. p.33).

Conforme Dardot e Laval, à medida que o flanco do próprio Estado age para diminuir e enfraquecer os direitos dos trabalhadores, e privatizar as receitas das suas instituições públicas, o mesmo 'terceiriza' também as suas responsabilidades na continuidade do contrato social com o Estado. No mesmo sentido, aos poucos o movimento de retirada do Estado é, sistemicamente, colonizado por novos modelos sociais de concorrência e de governabilidade empresarial (DARDOT; LAVAL, 2016, p. 26). É a partir desse momento que a precariedade da vida e dos dilemas existenciais dos trabalhadores sobre o alcance da produtividade (ou o esgotamento da capacidade produtiva desses) se intensificam no modo de sustentabilidade da vida neoliberal.

A adoção desses novos padrões induz a novas exegeses de desempenho e a outros estados de neutralidade subjetivos, no qual o "consentimento dos governados" vai se tornando um ato meramente superficial (CHOMSKY, 1999, p. 25). Nesse ponto, relembramos a essência política liberal, novamente reconstruída como estratégia de ordem psicossocial, e que cumpre a principal função ideológica no neoliberalismo: "se o individuo é o único responsável pelo seu destino, à sociedade não lhe deve nada. [..] Em compensação, ele deve mostrar constantemente o seu valor para merecer as condições de sua existência". (DARDOT; LAVAL, 2016, p. 213). 
Na perspectiva liberal, a teoria do "igualitarismo material", proposta por Karl Popper em "A sociedade aberta e seus inimigos" $(1962)^{10}$, insiste nessa mesma hipótese de mascarar as desigualdades produzidas pelo fracasso do sistema econômico: oferecer oportunidades iguais para capacidades sociais diferentes de aproveitamento. Dito de modo objetivo acreditase que a liberdade desacompanhada de oportunidades sociais não acrescenta nada a ninguém. Principalmente no que tange à política de mercado desigual entre os gêneros, adotada por algumas empresas que exploram o recurso da terceirização. Pelo contrário, o neoliberalismo assimilado pelas dinâmicas excludentes do trabalho social pode provocar um acentuado desgaste psicológico.

A dinâmica laboral dos trabalhadores atualmente está associada a uma rotina estafante de estímulos, muito além do que alguns indivíduos conseguem absorver. Isso acaba contribuindo para um comprometimento maior da saúde do trabalhador e da sua vitalidade funcional. Não há como barganhar contra as leis de operosidade do sistema neoliberal, posto que a violência implicada por essa ordem seja referenciada pelas próprias noções de liberdade dos indivíduos. Para que o indivíduo seja livre para conquistar a independência econômica, ele deve dedicar-se cada vez mais ao trabalho. Deve também aprender a fazer sacrifícios e assumir a responsabilidade por ser exatamente que é (HAN, 2015, p.27). Caso não esteja agindo "colaborativamente" de modo aceitável, ou seja, caso o seu esforço não alcance o sucesso e o reconhecimento esperados, certamente não está fazendo a sua parte como deveria. A mensagem propalada é a da meritocracia junto da hiper-responsabilização sobre si mesmo, até pelas crises que estão além da sua capacidade profissional em superá-las.

A rebelião contra a submissão ideológica às leis do capital é quase inescapável, isso porque a neoliberalização enquanto projeto, propõe a substituição da consciência plural pelo pensamento singular em relação à cidadania. Ensina-nos que para ser incluído e poder pertencer eu, sumariamente, devo excluir ou tomar o outro como adversário. Há momentos em que os outros e o próprio self do "sujeito do desempenho", se tornam uma razão-limitante para que o seu progresso não aconteça.

${ }^{10} \mathrm{O}$ igualitarismo é uma filosofia política que acredita na imparcialidade de tratamento entre os cidadãos pelo Estado. Acredita que o nascimento, a conexão familiar ou a riqueza não influenciem aqueles que criam e administram as lei. Não reconhece privilégios "naturais", embora certos privilégios possam ser conferidos pelos cidadãos àqueles em que confiam."The Open Society And Its Enemies”. POPPER, Karl R. (1962). Volume I. Plato's Political Programme. Chapter 6: Totalitarian Justice. IV, p. 100. 
Em regra, as mulheres demonstram incorporar melhor a plasticidade das demandas neoliberais exigidas, pois moldam seus corpos e o tempo de forma diversa ao serem submetidas às tensões dos mercados. Passam a incorporar multi tarefas ou a cumular empregos para cobrir a renda familiar. Ainda que ambos os gêneros devam se responsabilizar pelo sustento financeiro da família, são às mulheres as mais demandadas pelo planejamento, a execução e a administração de jornadas laborais que exigem altas expectativas de rendimento (FRASER, 2009, p.17). Por de trás da manutenção das prioridades familiares, há um sintoma neoliberal que vincula necessidades individuais femininas à rentável participação destas nos mercados de trabalho remunerados. Em especial, ao exercício de funções precarizantes como terceirizadas, e pouco gratificadas nos serviços gerais de limpeza (em manufaturas e confecções de roupas).

Para FRASER (2009, p.20), isso se deve ao modelo anterior de referência paternalistafamiliar do modelo welfarista ${ }^{11}$. Neste arquétipo social, os homens eram os únicos a subsidiar proventos domésticos enquanto o sistema de produção capitalista ainda era, em sua maioria, regulado pelo Estado. $\mathrm{Na}$ atual concepção neoliberal, há notadamente uma maior flexibilização capitalista sobre a distribuição de tarefas, que atualmente oneram mais as rotinas de desempenho das mulheres. Deste modo, as trabalhadoras passam a ser mais exigidas nesse novo modelo estratificado de compor a renda e o trabalho, sem que se sintam desobrigadas de dar conta dos afazeres domésticos.

Nesse sentido, a adoção de jargões neoliberais ${ }^{12}$ pelas empresas também buscam resignificar os processos trabalhistas e encobrir a existência de uma nova cultura organizacional exigida dos trabalhadores. Na gestão neoliberal, os trabalhadores passam a ser tratados como colaboradores (que é um sinônimo para empregado ou funcionário). As competências (habilidades) oferecidas pelos trabalhadores devem agregar valor (incorporar ao trabalho algo que o qualifique ou o torne cada vez mais sofisticado) aos contratantes. O serviço prestado deve atender ao "deadline" (prazo final) e a uma maior comoditização (um

\footnotetext{
${ }^{11}$ A crítica feminista a esse sistema econômico buscava aprofundar relações entre a cultura e a política, rejeitando as desigualdades do antrocentrismo na divisão sexual do trabalho.

${ }^{12}$ Informações disponíveis:<http://www.ihu.unisinos.br/78-noticias/581859-101-eufemismos-do-glossarioneoliberal> Acesso: 02-fev-2019.
}

Revista de Direitos Humanos e Efetividade | e-ISSN: 2526-0022| Porto Alegre | v. 4 | n. 2 |

p. 73 - 93 | Jul/Dez. 2018 
tratamento padrão para atividades ou produtos), para que melhor atendam as necessidades dos usuários.

O glossário neoliberal também apresenta as características mais desejadas pelos contratantes, que incluem "Pensar fora da caixa" (ter ideias diferentes das convencionais e propor soluções para problemas operacionais) e performatizar resultados (ter bom desempenho esperado no trabalho). Além disso, o trabalhador deve apresentar-se como um profissional proativo (tomar iniciativas sem esperar ordens) ao invés de só enxergar coisas que o deixem insatisfeito na empresa. O esforço e a "entrega pessoal" do trabalhador não devem ser distinguidos por cor nem gênero. $\mathrm{O}$ compromisso com o serviço deve estar em primeiro plano, independentemente, da condição de ter ou não filhos, da nacionalidade, do grau de instrução, etnia, estado civil, idade ou orientação sexual do trabalhador. Na prática, esses jargões acabam colaborando para a romantização das experiências de privação e sofrimento dos trabalhadores, diante das suas carências ou limitações pessoais.

Conforme (HAN, 2015, p. 15), essa situação persecutória entre a positividade e as crenças individuais no mundo do trabalho, criam ambições que separam a força dos trabalhadores. Além de dividir espaços, a subjetividade neoliberal vem produzindo gerações de indivíduos depressivos e esgotados de perspectivas. Desta forma, o culto a performance empresarial vai alargando a depressão como sintoma social. Quem não se adapta bem a essas mudanças neoliberais, tem a sensação de estar à "margem da experiência", do ritmo social (KEHL, 2009, p. 171). O depressivo é àquele que "resiste com sua lentidão, seu mergulho angustiado e angustiante em um tempo estagnado, que lhe parece não passar”.

A respeito disso, a Organização Pan Americana da Saúde $^{13}$ revela que a depressão é o transtorno mental mais incapacitante do mundo, além de induzir um alto índice de pessoas ao suicídio. Estima-se que 300 milhões de pessoas no mundo sejam afetadas por essa condição, seguida do Transtorno bipolar - 60 milhões, pela esquizofrenia e outras psicoses - que juntas, somam um quadro de 23 milhões de indivíduos. No Brasil, a incidência de transtornos mentais reservada à atividade do trabalho, supera o índice de 612 mil pessoas prejudicadas.

\footnotetext{
${ }^{13}$ Dados extraídos pela Associação Pan Americana e pela Organização mundial da Saúde $<$ https://www.paho.org/bra/index.php?option=com_content \&view=article\&id=5652:folha-informativatranstornos-mentais\&Itemid=839> Abril/2018. Consultado em: 01-ago-2018.
}

Revista de Direitos Humanos e Efetividade | e-ISSN: 2526-0022 | Porto Alegre | v. 4 | n. 2 |

p. 73 - 93 | Jul/Dez. 2018 
Além de ser responsável pela morte de 2.500 pessoas ao ano, de acordo com último Anuário Estatístico da Previdência Social ${ }^{14}$. Revelando dados sociais de grande impacto aos setores sociais, culturais, ambientais, sanitários e político-econômicos para o país.

Nesse sentido, HAN (2015) caracteriza o sujeito neoliberal como autor e vítima do mesmo contexto de violência existencial. A sutileza do estado mental produzido pelo neoliberalismo é permitir que os trabalhadores reifiquem o seu comprometimento laboral, moral e psicológico não apenas com o sistema, mas consigo mesmo e com os limites de alcance do seu potencial. O efeito imediato disso é a experiência de sofrimento constante, fato que aumenta as chances de infartos psíquicos, da depressão e da morte subjetiva de todos os sentidos positivos da vida. (HAN, 2015, p. 14). Esvaziam-se os afetos, os vínculos de fraternidade das relações trabalhistas, responsáveis pelo fenômeno da atomização da sociedade (HAN, 2015).

Torna-se difícil dissociar tais violências psicológicas principalmente quando o poder ilimitado sobre os corpos e as mentes dos trabalhadores e das trabalhadoras age sem cancelar o dever da disciplina nem o da obediência. Uma forma de autocontenção dos indivíduos que conta com a subjetivação do trabalho como um novo imperativo categórico para si mesmo. Uma lei vigilante de conteúdo moral a ser perseguida. Observando de modo prático, destacase, por exemplo, a forma utilitária de como são tratadas às jornadas de trabalho feminino. Além de serem subserventes ao modo produtivo das demandas corporativas em funções precárias, acabam recebendo verbas salariais menores.

A internalização do modo operário inconsciente, que disciplina o sujeito do desempenho à vontade mística da lei, nada mais é do que a manifestação do espírito psicológico do capitalismo, descrito por Boltanski; Chiapello (2005) sobre as idiossincrasias, em especial, a dos movimentos feministas (FRASER, 2009, p.24). A luta histórica das mulheres contra as relações de poder masculino e contra a distorção cultural (construída) sobre a função de si próprio enquanto sujeito, é parte do mundo do trabalho remunerado. É parte também da continência que há entre o trabalho doméstico como forma de reprodução simbólica: gera um dever-ser comportamental, e outro institucional.

\footnotetext{
${ }^{14}$ Anuário Estatístico da Previdência Social/Ministério da Fazenda, Secretaria de Previdência, Empresa de Tecnologia e Informações da Previdência - Ano 1 (1988/1992) - Brasília: MF/DATAPREV (2015) <http://www.previdencia.gov.br/wp-content/uploads/2015/08/AEPS-2015-FINAL.pdf> Consulta: 01-ago-2018.
} 
Essas relações de gênero quando expostas, consequentemente, desvinculam as mulheres do trabalho material ao mesmo tempo em que desafiam as suas condições em conciliar rotinas profissionais e familiares. De tal forma que, "não estamos mais lidado com um simples desencantamento democrático passageiro, mas com uma mutação muito radical, cuja extensão é revelada pela desimbolização que afeta a política" no mundo da vida e dos direitos das populações mundiais (DARDOT; LAVAL, 2016, p. 382).

\section{NEOLIBERALISMO E AS ESTRATÉGIAS DE DESEMPODERAMENTO FEMINISTA NO CENÁRIO TRABALHISTA GLOBALIZADO.}

Conforme visto antes, a sociedade disciplinar descrita por Foucault (FOUCAULT, 1987) refletia sobre a experiência universalizante do capitalismo como centralizador do poder Estado. Contudo, esquecera-se de destacar que esse mesmo modelo civilizatório sempre fora revestido por hierarquias patriarcais (FRASER, 2009, p.17). É importante esclarecer que por “capitalismo organizado pelo Estado", refere-se à formação social, cultural e política do pósguerra em que os Estados desempenharam o monopólio dirigista de suas economias nacionais. Este modelo governista foi arquitetado pelo planejamento de bem-estar welfarista androcêntrico, e também se estendia sobre a divisão social do trabalho (remunerado/ não remunerado).

O modelo econômico welfarista foi esboçado pelas medidas desenvolvimentistas do Bretton Woods (1944) ${ }^{15}$, e começou a entrar em crise a partir do final dos anos de (19601970). Isso aconteceu quando as vantagens associadas a esse modelo passaram a ser questionadas quando a divisão de espaços políticos, a normatização social, e a visão restritiva da justiça começavam a comprometer a efetividade dos direitos sociais (FRASER, 2018, p.18).

Em um primeiro momento, esse modelo de governança buscava separar espaços públicos e privados para designar diferentes obrigações trabalhistas aos gêneros. O

\footnotetext{
${ }^{15}$ É um sistema normativo convencionado para facilitar relações comerciais, regular a política econômica e financeira entre os países mais industrializados do mundo. Bretton Woods estabeleceu o Banco Internacional para a Reconstrução e Desenvolvimento (International Bank for Reconstruction and Development, ou BIRD) fruto da demanda de recuperação dos países pós-guerra. Criou o Banco Mundial e o Fundo Monetário Internacional (FMI).
}

Revista de Direitos Humanos e Efetividade | e-ISSN: 2526-0022 | Porto Alegre | v. 4 | n. 2 |

p. 73 - 93 | Jul/Dez. 2018 
movimento feminista, por exemplo, se destacava no modelo Welfarista por criticar o papel político designado às tarefas disciplinares sobre os ofícios de gênero (FRASER, 2009, p.21).

A postura antiperialista adotada pela segunda onda do movimento era a de censurar o papel dos homens como provedores econômicos, e o reservado às mulheres, como provedoras de cuidados (maternos) com a entidade familiar.

A grande revolução da segunda onda do movimento feminista ${ }^{16}$ exigiu a inclusão profissional das mulheres, mas não previu que a conquista dessa exigência não influenciaria tanto na luta pelo reconhecimento de pautas igualitárias sobre a repartição das funções em âmbito doméstico. Se hoje em dia há uma sensação de maior aceitação democrática (entre a cultura igualitária e a ideia que perseguimos em torno da mensagem dos Direitos Humanos), isso se deve a grande contribuição da segunda onda do movimento feminista. Por um lado, lançaram-se condições políticas para que as mulheres avançassem na luta contra as injustiças ligadas a classe e raça (localizadas na família, na cultura e na sociedade civil). Por outro, tornaram-se protagonistas de uma política do desempenho neoliberal que se alimenta do discurso do empoderamento e da "cultura de superação" ${ }^{17}$, mais exigida das mulheres.

Ademais, quando as mulheres passaram a ingressar no mercado de trabalho, as demandas associadas às rotinas domésticas e familiares não desapareceram da órbita de suas obrigações sociais. A transição critica do modelo welfarista é substancial à luta feminista nesse período, pois, desafiar o modelo cultural imposto pelo sistema econômico, causou o fardo de serem mais exigidas nesse novo modelo de gestão social-igualitário no trabalho. A luta pela independência das mulheres nos mercados capitalistas não apenas conquistou o direito a renda própria, mas também a reorganização do tempo e das funções de cuidado na gestão familiar. Se antes os espaços ocupados pelas mulheres na sociedade facultavam-lhes valor econômico e simbólico, hoje, são mais exigidas que antes em performatizar tarefas

\footnotetext{
${ }^{16}$ Iniciou na década de 1960 nos EUA impulsionada pelo movimento dos Direitos Civis, e, eventualmente se espalhou por todo ocidente. Nos Estados Unidos, o movimento convergiu com a ascensão do neoliberalismo e durou até o início da década de 1980.

${ }^{17} \mathrm{Na}$ obra: "Sociedade do cansaço" de (HAN, 2015) tenta conceituar a violência neuronal ${ }^{17}$, como uma tentativa de definição do indivíduo contemporâneo. A cultura de superação encarada ao extremo está associada a esforços físicos, pressão psicológica e a depressão, e pode ser encarada como a tragédia da insuficiência do sujeito nas sociedades neoliberais.
} 
(domésticas, familiares, profissionalizante) recebendo cada vez menos pelo seu trabalho remunerado. Se antes as estratégias feministas focavam em radicar slogans como: "O pessoal é político" "18 a pretensão da segunda onda buscava "usar a política para domesticar mercados" No fim, a nova fórmula política do capitalismo neoliberal usou os mercados para domesticar a política (FRASER, 2009, p.18) ${ }^{19}$ ” de gênero a favor da concorrência do mercado.

Entre 1960-1980 as pautas identitárias dos movimentos feministas pareciam aflorar no mundo inteiro, em consonância com a cultura política e econômica de resistência antiimperialista da época (GONÇALVES, 2009, p. 104). Os movimentos adotaram um posicionamento político de desafio à cultura, mas que não se manteve em relação ao plano econômico e às graves retaliações internacionais ${ }^{20}$ (FRASER, 2009, p.20). A intenção inicial incluía a luta pelo reconhecimento da diferença entre os gêneros, enxergada como questão de justiça distributiva. No entanto, “[..] na prática, a tendência era subordinar as lutas socioeconômicas às pautas de reconhecimento, enquanto na academia, a teoria cultural feminista começou a obscurecer a teoria social feminista (FRASER, 2009, p.23)". O efeito disso foi um desligamento histórico das memórias sociais sobre o conceito de igualdade de direitos civis às mulheres. $\mathrm{O}$ fato de os movimentos feministas protagonizarem mais as suas críticas em direção à cultura, nos afastou do enfrentamento político aos setores empresariais, do capitalismo androcentrista, do estatismo e do próprio modelo Westfalianista. Isso indica que acabou promovendo um esvaziamento do Estado social à margem daquele período histórico (1969-1980).

É nesse sentido que cabe brevemente salientar sobre a contribuição revolucionária dos movimentos estudantis e dos seguimentos universitários à democracia, no episódio francês que ficou conhecido como 'Maio de 1968'21. A intenção destes movimentos beligerantes contava com a participação estudantil, a dos sindicatos, de artistas e grupos intelectuais na luta por ideais iluministas (GONÇALVES, 2009, p.99). No entanto, ainda que tenha sido

\footnotetext{
${ }^{18}$ Referência ao feminismo radical de Carol Hanisch, e ao seu slogan mais conhecido (1960).

${ }^{19}$ A expressão indica usar o controle forte dos governos para orientar politicamente as economias, do contrário do que tem sido feito sob a ótica neoliberal.

${ }^{20} \mathrm{~A}$ luta dos movimentos feministas se vinculava às injustiças trans-fronteiriças como a Guerra do Vietnã. É nesse momento que a crítica de gênero foi entrelaçada com a crítica ao imperialismo.

${ }^{21}$ Disponível em: <https://www.cartacapital.com.br/internacional/revolucao-sexual-de-maio-de-68-201cnuncaaconteceu201d-dizem-especialistas> acesso em: 08.set.2018.
} 
consagrado nas páginas da história como um episódio revolucionário mundial, acabou causando apenas efeitos políticos adesivos e de caráter social transitório. Isso porque o movimento não tinha uma única causa identitária comum que conseguisse conciliares revisionistas da esquerda com: socialistas, trotskistas, maoístas, anarquistas, surrealistas e marxistas. Alguns deles se designavam tão anticomunistas como anticapitalistas ${ }^{22}$. Como esse episódio poderia combater referenciais masculinistas da tradição hegemônica do capitalismo, se os principais representantes do movimento "maio de 68" eram homens (GONÇALVES, 2009, p.100). Por mais que esse episódio tenha percorrido o mundo todo, não trouxe intenções de começar uma revolução sexual de total ruptura com a cultura.

Em meio às expectativas sobre o rumo dos movimentos e a omissão do Estado em garantir os direitos fundamentais sobre os gêneros, essas demandas se fortalecem no discurso capitalista pela "crítica feminista do paternalismo burocrático (do Estado), recuperada pelo neoliberalismo (FRASER, 2009. p, 27)". Com o tempo, o gerencialismo capitalista reestruturou as demandas sociais sobre uma nova proposta econômica e sociocultural. Surge a partir daí um novo método de enquadrar a vida e a cidadania pela gestão empresarial. A nova gestão disciplinar do neoliberalismo proporia "[..] um novo capitalismo "conexionista", "de projeto", no qual as hierarquias organizacionais rígidas dariam lugar a equipes horizontais e a redes flexíveis, liberando, assim, a criatividade individual” (FRASER, 2009, p. 24). O objetivo dessas tecnopolíticas foi resgatar o sexismo e instrumentalizá-lo como técnica autodisciplinar para o trabalho.

Enquanto o cultural permanece como a discussão principal dos movimentos feministas, o sujeito neoliberal continua sendo o sujeito masculino, branco e economicamente privilegiado pelas formações universitárias. É o principal alvo dos discursos eleitorais ${ }^{23}$. Nesse horizonte neoliberal de se (re)pensar as relações trabalhistas e a divisão sexual do trabalho (terceirizado), não é mais obrigação do Estado interferir nas relações de desigualdade a seguimentos minoritários. Isso ocorre quando a iniciativa econômica tenta delimitar uma nova lógica de interesses, onde o papel do Estado estará disponível para tutelar uma parcela de direitos à parte da população (DARDOT; LAVAL, 2016, p.378).

\footnotetext{
${ }^{22}$ Informações extraídas da reportagem:<https://www.nexojornal.com.br/explicado/2018/05/05/Maio-de-1968as-origens-e-os-ecos-do-movimento $>$ Acesso em: 11-nov-2019.

${ }^{23}$ Disponível em: <https://www.revistaforum.com.br/se-empresas-pagam-salarios-distintos-para-homens-emulheres-estado-nao-deve-interferir-diz-joao-amoedo/> 08.Set.2018.
} 
Em contrapartida, as trabalhadoras mulheres são àquelas tantas, indispensáveis, que ocupam postos de trabalho cada vez mais desproporcionais e estratificados nas empresas. E essa seleção produtiva não intersecciona apenas uma espécie da categoria gênero. Nas palavras de Fraser, as mulheres afetadas "não são apenas jovens mulheres solteiras, casadas e com filhos; não só as mulheres racializadas, mas virtualmente mulheres de todas as nacionalidades e etnias (2009, p. 25)".

"[..] Como tais, as mulheres despejaram-se em mercados de trabalho ao redor do globo; o efeito foi cortar na raiz de uma vez por todas o ideal do salário familiar do capitalismo organizado pelo Estado. No capitalismo neoliberal "desorganizado", este ideal foi substituído pela norma da família de dois assalariados. Não importa que a realidade que subjaz o novo ideal sejam os níveis salariais decrescidos, diminuição da segurança no emprego, padrões de vida em declínio, um aumento abrupto no número de horas trabalhadas em troca de salários por família, exacerbação do turno dobrado agora frequentemente um turno triplo ou quádruplo - e um aumento de lares chefiados por mulheres. O capitalismo desorganizado vende gato por lebre ao elaborar uma nova narrativa do avanço feminino e de justiça de gênero (FRASER, 2009. p, 25)”.

Paradoxalmente, hoje o movimento feminista enfrenta crises de valores ético identitários sobre o próprio futuro. Se por um lado contabiliza-se uma forte politização do pessoal, a partir da abertura discursiva ao empodermento político e econômico, por outro, criam-se rachaduras em outros contextos, onde violências sociais mais periféricas parecem escapar, à primeira vista, de uma critica bem acurada sobre a precarização de gênero e de classe convencionais.

De um lado temos o feminismo "classe média" que é, predominantemente, academicista e branco. Luta pela igualdade salarial e pela ascensão de melhores postos de trabalho para as mulheres nos mercados globais, (algumas de suas pautas). Do outro, temos a condição das trabalhadoras periféricas, terceirizadas, estratificadas em cargos de baixa remuneração. Podem ser trabalhadoras domésticas, sexuais ou que prestam serviços de limpeza. Todas essas realidades de exploração buscam não apenas alcançar os benefícios da segurança jurídica e da emancipação cultural da misoginia, mas também livrar-se tradicionalmente da violência econômica, algo que convive muito bem com outras formas de violência neoliberal. (FRASER, 2009, p.26).

É claro que não se está tentando estabelecer prioridades ao criticar a ordem de proteção aos Direitos Humanos das mulheres. Que muito se voltam a condenar as práticas

Revista de Direitos Humanos e Efetividade | e-ISSN: 2526-0022 | Porto Alegre | v. 4 | n. 2 |

p. 73 - 93 | Jul/Dez. 2018 
violentas do machismo e a biolítica reprodutiva sobre os corpos femininos. Ocorre que, quando o fazemos, estamos reproduzindo o mesmo contexto separatista de direitos que remonta o capítulo da Guerra Fria. De um lado está a luta pela inclusão dos direitos civis e políticos, do outro a conquista dos direitos sociais e econômicos de gênero (FRASER, 2009, p. 28). Isso nos leva a duvidar sobre o percurso de evolução que os movimentos feministas têm adotado. Dito isso, em comparação à abordagem combatente, de caráter político, que parece ter estacionado nas pautas de mobilização individual. Talvez as correntes feministas tenham errado em não se compreender na simultaneidade de violências a partir da experiência econômica. Às mesmas violências que foram subjulgadas no passado e no presente, continuam associadas à classe, raça e outros marcadores sociais.

Entendemos que algumas manifestações simbólicas se consolidam culturamente de formas invisíveis. A violência econômica associada ao adoecimento psíquico dos trabalhadores se impõe como algo diferente. Passa pela compreensão de que a pauta econômica assume, no mundo atual, o entendimento de que é a maior das violências experimentais em nossa sociedade. Não se pretende com isso dizer que não há espaços a ocupar pelos movimentos feministas, na luta pela justiça e contra a institucionalização de demandas sociais de base econômica. As mesmas que colonizam os sistemas jurídicos e se apropriam das demandas populares, revestidas na legalidade. Ainda que a estratégia de resistência adotada pelos movimentos sociais seja a linha defensiva, o seu propósito é impedir o esvaziamento do significante político, o enfraquecimento das democracias e das instituições que operam dentro do seu sistema representativo da política institucional.

É nesse sentido que as críticas apontadas aos movimentos feministas pretendem alertar sobre a reprodução tóxica que tem sido feita, e que escraviza mulheres ao reduzi-las, discursivamente, ao produzir novo 'dever-ser' no capitalismo corporativo. No entanto, esse plano econômico não deixa às claras qual será o papel produtivo das mulheres, investido nesse novo pacto social, para o futuro das relações trabalhistas e democráticas. Ao que tudo indica, "Como o discurso se torna independente do movimento, ele é progressivamente confrontado com uma estranha versão sombria de si mesma, um cópia sinistra que nem se pode simplesmente abraçar, nem negar completamente (FRASER, 2009, p. 29)”.

CONCLUSÃO:

Revista de Direitos Humanos e Efetividade | e-ISSN: 2526-0022 | Porto Alegre | v. 4 | n. 2 |

p. 73 - 93 | Jul/Dez. 2018 
Conforme os padrões neoliberais britânicos, "a Lei é um conjunto de normas escritas, mas também existem outras normas não escritas, que constituem o terceiro elemento essencial ao funcionamento do capitalismo, e que podem ser resumidas em uma palavra: Cultura" (TATCHER, 2005, p, 451). Ainda que invisível na constituição da experiência, à invisibilidade ideológica do neoliberalismo, sob a qual se arrasta esta escrita, é uma tentativa de tornar a imaterialidade abstrata da vida, autorregulada pelos parâmetros tecnopolíticos, em uma forma violência pronunciável. É sob o mesmo esforço sensível que Dardot e Laval (2016) tentam conceituar a violência psicológica com a violência econômica, como fenômenos que convergem com a substituição da alteridade por outro tipo de reação, algo mais adaptado ao cenário hostil. E que a cada dia internaliza mais hábitos de desengajamento, conforme tratamos antes, em relação ao sistema econômico e a ação dos governos. A universalização da experiência neoliberal inviabiliza o diálogo sobre a experiência corpórea e sensorial de inúmeros trabalhadores e trabalhadores sobre o desgaste provocado pelo sistema. E a experiência de sofrimento constante faz aumentar as chances da depressão e da morte de todos os sentidos positivos da vida. (HAN, 2017, p. 14).

A internalização do modo operário inconsciente, que disciplina o sujeito do desempenho à vontade mística da lei, nada mais é do que a manifestação do espírito psicológico do capitalismo, descrito por Boltanski, Luc; Chiapello (2005) sobre as idiossincrasias, em especial, a dos movimentos feministas. A luta histórica das mulheres contra as relações de poder masculino e contra a distorção cultural (construída) sobre a função de si próprio enquanto sujeito, é parte do mundo do trabalho remunerado. É parte também da continência que há entre o trabalho doméstico como forma de reprodução simbólica de um dever-ser comportamental, e outro institucional. Algo que, consequentemente, desvincula as mulheres do trabalho material ao mesmo tempo em que desafiam as suas condições em conciliar rotinas profissionais e familiares. Desta forma, conclui-se que a luta pela igualdade de direitos e pelos Direitos Humanos das mulheres não evoluirá sem que haja o combate à violência de ordem econômica, que passa pela compreensão de que suas pautas não devem se submeter às barganhas do poder político. Posto que, é esse mesmo tipo de violência que 
produz e perpetua estágios inconscientes (e sexistas) de representação social. Não haverá transformação sem que as raízes da opressão sejam tratadas com efeitos paliativos.

Conforme visto, a incalculabilidade do neoliberalismo já se orienta sob as ramificações do direito, e, deste modo, disciplina a lógica dos comportamentos sociais, o controle dos afetos, do corpo, dos gêneros e da vida política, e de todos que dependem da confiabilidade no sistema. De tal forma que, "não estamos mais lidado com um simples desencantamento democrático passageiro, mas com uma mutação muito radical, cuja extensão é revelada pela desimbolização que afeta a política" no mundo da vida e dos direitos das populações mundiais (DARDOT; LAVAL, 2016, p. 382).

\section{REFERÊNCIAS:}

BOLTANSKI, Luc \& CHIAPELLO, Ève. The new spirit of capitalism. Londres, Nova Iorque: Verso, 2005 [O novo espírito do capitalismo. São Paulo: Martins Fontes, 2009].

CHOMSKY, Noam. O Lucro ou as pessoas: Neoliberalismo e a Ordem Global. (1999) Ed. BERTRAND BRASIL - 2012.

DARDOT, Pierre; LAVAL, Christian. A nova razão do mundo. Ensaio sobre a sociedade neoliberal. São Paulo: Ed. Boitempo, 2016.

FOUCAULT, Michel. Vigiar e Punir: Nascimento da Prisão. Petropolis: Ed. Vozes, 1987.

FRASER, Nancy. O feminismo, o capitalismo e a astúcia da história. Dossiê: Contribuições do pensamento feminista para as Ciências Sociais. Mediações, Londrina, v. 14, n.2, p. 11-33, Jul/Dez. 2009.

GONÇALVES, Renata. Sem pão e sem rosas: do feminismo marxista impulsionado pelo Maio de 1968 ao academicismo de gênero. Revista eletrônica Lutas sociais. Núcleo de Estudos de Ideologias e Lutas Sociais (NEILS). Programa de Estudos Pós-Graduados em Ciências Sociais - PUC/SP: n. 21/22 (2009) $<$ https://revistas.pucsp.br/index.php/ls/article/view/18620> Acesso em: 08. Set.2018.

HAN, Byung-Chul. A Sociedade do cansaço. Petrópolis, RJ: Ed.Vozes, 2017. 
KEHL, M. R. O Tempo e o Cão: A atualidade das depressões. 1ed. São Paulo: Boitempo, 2009.

SAFATLE, Vladimir. O círculo dos Afetos: Corpos políticos, desamparo e o fim do indivíduo. São Paulo: Cosac Naify, $1^{\text {a }}$ Ed. 2015. 512p.

THATCHER. Margaret Hilda. A arte de governar: Estratégias de um mundo em desenvolvimento. Tradução de Gleuber Vieira. Rio de Janeiro: Ed. Bibliografia do Exercito, 2005. 